\title{
Laboratory methods for case finding in human psittacosis outbreaks: a systematic review
}

\author{
Annelies A. Nieuwenhuizen ${ }^{1}$ (D), Frederika Dijkstra ${ }^{1 *}$, Daan W. Notermans ${ }^{2}$ and Wim van der Hoek ${ }^{1}$
}

\begin{abstract}
Background: Psittacosis outbreak investigations require rapid identification of cases in order to trace possible sources and perform public health risk assessments. In recent outbreaks in the Netherlands, such investigations were hampered by the non-specificity of laboratory testing methods to identify human Chlamydia psittaci infections.
\end{abstract}

Method: A systematic search of PubMed and Scopus databases of literature published between 01 January, 1986 and 03 July, 2017 was done to find best practices of laboratory-testing methods used in psittacosis outbreaks of two or more human cases. Reference lists of included articles were hand searched to identify additional articles.

Results: Thirty-seven eligible articles were identified, describing 44 human psittacosis outbreaks in 12 countries. Laboratory tests performed were PCR (with various targets), serologic tests (complement binding reactions, ELISA's, immunofluorescence tests and immuno-peroxidase tests) and culture, in various combinations. The literature provided no 'gold standard' laboratory testing strategy to identify recent human C. psittaci infections. In most psittacosis outbreaks, for a considerable number of cases (or tested individuals in an exposed cohort), C. psittaci infection could not be confirmed, nor excluded as causative pathogen. None of the testing strategies was found to be suitable for (nearly) full case finding.

Conclusion: PCR enables rapid identification of human psittacosis patients and helps source finding by genotyping but has the disadvantage that sensitivity is high only in the acute phase. In outbreak situations, there is often a time delay and therefore, there is a need for new serologic testing methods next to PCR, with good specificity and sensitivity. Moreover, serum is easier to collect than the preferred diagnostic materials for PCR. A serologic test that can reliably confirm infection status without the necessity of convalescent serum sampling would enhance case finding, source tracing, identification of risk factors and assessment of burden of disease in various settings.

Keywords: Psittacosis, Chlamydia psittaci, Diagnostics, Disease outbreaks, Epidemiology, Systematic review, Zoonoses.

\section{Background}

Psittacosis is a zoonotic disease, which regularly causes small outbreaks worldwide. Traditionally, psittacines (parrot-type birds) have been considered as reservoir of the causative bacterium, Chlamydia psittaci. In addition, many other birds, including wild birds and commercially kept poultry, have also been implicated [1].

\footnotetext{
* Correspondence: frederika.dijkstra@rivm.nl

${ }^{1}$ Centre for Infectious Diseases, Epidemiology and Surveillance, Centre for Infectious Disease Control, National Institute for Public Health and the Environment (RIVM), Bilthoven, The Netherlands

Full list of author information is available at the end of the article
}

In the Netherlands, an outbreak occurred in 2007 among visitors to a bird show [2,3]. After confirmation of the diagnosis by real-time polymerase chain reaction (PCR) of three hospitalized patients, a retrospective cohort study among about 200 visitors was started. Serological screening and a questionnaire study were performed in order to estimate attack rates and identify risk factors. Based on screening immunoglobulins (Ig)(IgG/A/M) with a genus specific enzyme-linked immunosorbent assay (Chlamydia r-ELISA, Medac Diagnostika) and a complement fixation test (CFT) on sera taken 23 days after the

(C) The Author(s). 2018 Open Access This article is distributed under the terms of the Creative Commons Attribution 4.0 International License (http://creativecommons.org/licenses/by/4.0/), which permits unrestricted use, distribution, and 
bird show, the attack rate was very high (42/156, 27\%), but surprisingly none of the IgM concentrations of suspected infected visitors showed a significant rise after a mean of 14 days to confirm a recent infection. To verify the unexpected high attack rate, a set of control sera of 30 healthy volunteers was also tested with the same ELISA. Thirty percent of the single control sera showed an IgM response. None of these serological responses could be explained by zoonotic bird contact. It was unclear if this high seroprevalence was due to cross-reaction with other Chlamydia species, especially with Chlamydia pneumoniae or false positivity of the ELISA test $[2,4,5]$. The lack of a C. psittaci-specific antibody test therefore hampered a proper serological interpretation of the epidemiological outbreak investigation.

In 2012, similar problems occurred with investigation of another outbreak in the Netherlands with eight confirmed cases among visitors and volunteers working for a bird sanctuary. Three persons were hospitalized and diagnosed with pneumonia (including the index case). For the epidemiologic investigation of this outbreak, a cohort of more than a 100 volunteers as well as 3 payed workers was requested to fill in a questionnaire about demographics, symptoms, medical care sought, medication use, medical history and possible exposures. Out of 40 respondents who reported symptoms, 25 met the formulated clinical case definition for psittacosis of this outbreak. Convalescent serological samples of 19 cases were taken three times within a 3-4 week interval. Serology was performed on these samples for the identification of antibodies against $C$. psittaci (micro-immunofluorescence tests (MIF) IgG for $C$. psittaci) and to exclude other Chlamydia species (MIF IgG for C. pneumoniae, ELISA IgM/A/G for C. pneumoniae and MIF IgG for C. trachomatis). Six patients tested positive for $C$. psittaci with a fourfold rise in IgG titer. PCR for C. psittaci was used in 12 patients, of whom two tested positive. Nasal-pharyngeal swabs for PCR testing were taken three to 14 days after onset of symptoms with exception of a sputum sample of an intensive care (ICU) patient, which was taken after 22 days. PCR to exclude $C$. pneumoniae, Coxiella burnetii, and influenza virus A was performed in nine patients, who all tested negative for these pathogens [6](personal communication N. Reedijk 17-08-2016 and 21-03-2017).

This meant that despite the use of a combination of laboratory tests, $C$. psittaci could be confirmed in a small number of the suspected cases only. For majority of the cases tested, it remained unclear whether infection with $C$. psittaci was the cause of their symptoms. Therefore, in spite of the availability of extensive information from the questionnaire, formal epidemiological analysis lacked possibilities and was unsatisfactory. The difficulties with the laboratory diagnostics in this outbreak were amongst others related to omitting laboratory diagnostics for C. psittaci by physicians (patients are treated empirically), non-optimal sampling intervals (caused by medical consultation delay and sampling delay) and lack of suitable clinical material for PCR testing (no sputum or broncho-alveolar lavage (BAL) available for non-hospitalized patients) [4, 6], (personal communication N. Reedijk 17-08-2016).

Both outbreaks in the Netherlands showed the constraints in confirming human psittacosis cases with PCR-based diagnostics because of time delay, decline of sensitivity of PCR in time and/or unavailability of appropriate diagnostic material. Serology with convalescent sampling is the alternative to screen possible exposed persons.

The difficulties in interpreting laboratory findings in these outbreak settings prompted us to do a systematic review of the international literature on psittacosis outbreaks with special emphasis on the laboratory methods used, in order to find out which (combination of) laboratory testing methods could be advised for psittacosis outbreak investigations.

\section{Methods \\ Search strategy}

The search strategy we developed aimed to find descriptions of human psittacosis outbreaks with a special focus on diagnostic laboratory methods. We searched PubMed and Scopus for items published between 1 January 1986 and 3 July 2017, using MESH (Medical Subject Headings)and keywords psittacosis, Chlamydia or Chlamydophila psittaci, psittaci, outbreak", disease outbreaks, epidemiology, epidemic, human(s) and not animals. The complete search strategies are given in Additional file 1. All results were combined in one EndNote X8 file (Clarivate Analytics USA) and duplicates removed using EndNote and by hand. There was no language restriction in our search but we could only read full texts of selected articles in Dutch, English, German, French and Spanish. At a later stage, reference lists of selected full texts were checked to identify studies possibly missed by our search strategy. Finally, the Cochrane library was checked for systematic reviews that included information on the topic of our review with the keyword 'psittacosis' and keywords 'Chlamydia psittaci', without relevant results.

\section{In- and exclusion criteria}

Two authors (AN, FD) used a pilot search of PubMed with keywords 'psittacosis outbreak' to specify in- and exclusion criteria before the title and abstract screening. Figure 1 shows the definitive in- and exclusion criteria. In summary, articles describing an outbreak of human psittacosis with at least two possible human cases and with specification of the laboratory test methods used to confirm infection were included. Articles with description of psittacosis outbreaks among humans that took place before 1986 were excluded, because before that time, $C$. 


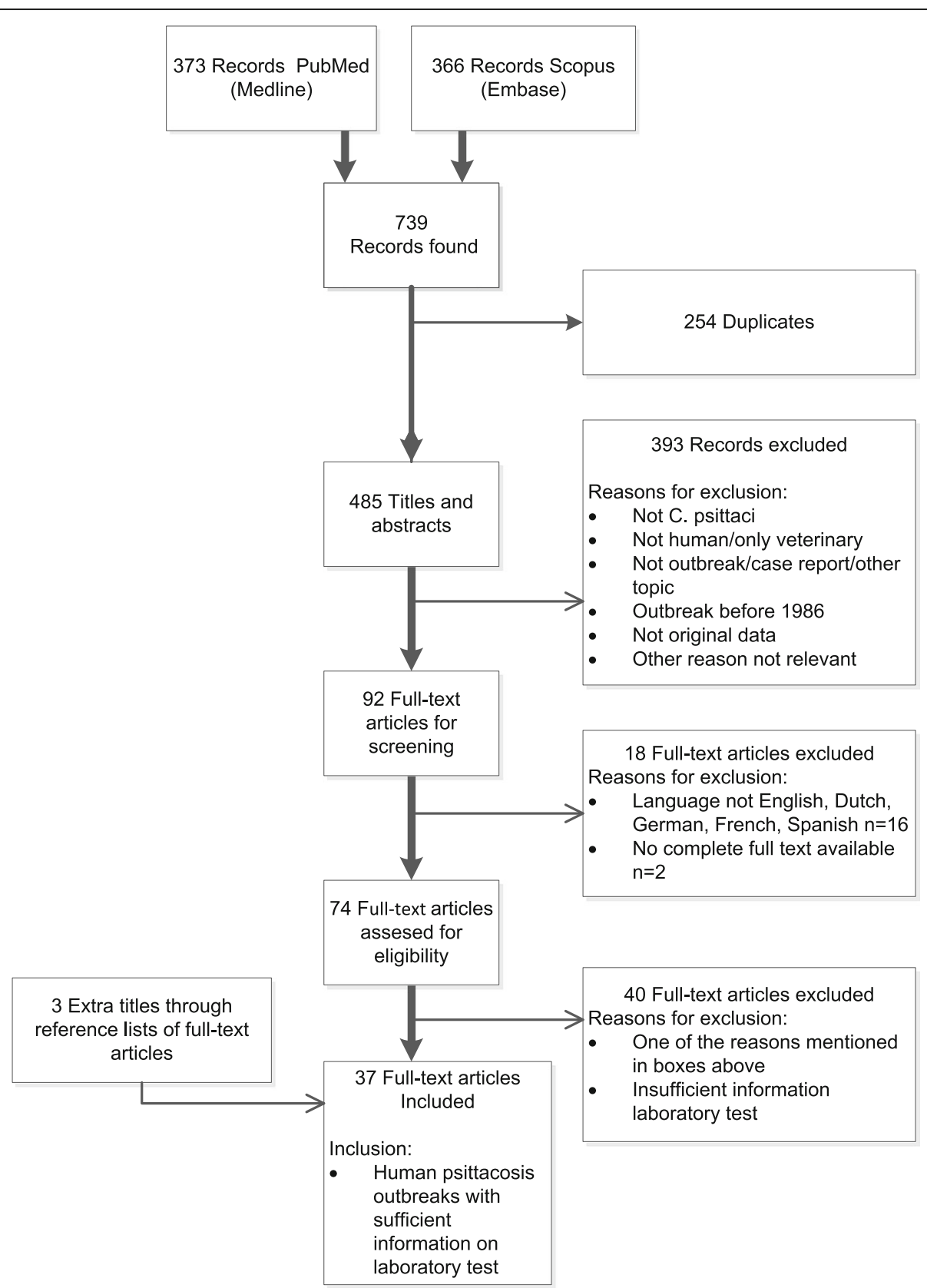

Fig. 1 PRISMA flow diagram of the systematic search and selection results

pneumoniae was designated as C. psittaci strain TWAR (Taiwan acute respiratory agent) $[7,8]$ and could not be differentiated from $C$. psittaci $[9,10]$. We also excluded single case reports and reviews or other publications not based on original data. We did not find any human outbreaks when articles mentioned C. psittaci as cause of abortion, ocular lymphoma or trachoma in the pilot search. Articles with these topics were therefore other reasons for exclusion. Full text articles, in which the type of laboratory tests that were used were not specified, were also excluded.

\section{Title and abstract screening}

In the first screening stage, the in- and exclusion criteria were applied to the titles and abstracts resulting from the literature search. This title and abstract screening was done independently by two investigators (AN, FD) for the PubMed and Scopus search results. PubMed and Scopus items were excluded when both authors considered them not relevant. An item was selected from PubMed or Scopus search for full text screening if at least one of the authors (AN, FD, WvdH) labeled it as possibly meeting the inclusion criteria. Articles without abstract were included 
for full text screening when the title seemed relevant. When at least one of the authors (AN/FD, AN/WvdH) had doubt about exclusion after the initial selection round of PubMed or Scopus database items for full text screening eligibility, a third author was consulted and disagreements solved by discussion.

\section{Full text screening}

In the second screening stage, the in- and exclusion criteria were applied to the full text articles that resulted from the title and abstract screening. Three authors (AN, FD, WvdH) did this independently. Disagreements about selecting an item were resolved by discussion between the authors (AN, FD, WvdH). This yielded the full text articles that were included in the review.

Reference lists of the selected full text were checked by hand to find extra titles that were missed by the search. These extra titles were screened for inclusion by the same method as the PubMed and Scopus titles.

\section{Data extraction}

We extracted the following data from the included articles: year and country of the outbreak, population and setting, the laboratory test(s) performed to diagnose $C$. psittaci infection in humans, number of patients tested as well as number of patients positive by the laboratory test. Data extraction was done by AN. Uncertainties were resolved by discussion between the authors (AN, FD, WvdH).

\section{Results}

\section{Characteristics of articles included for review}

Our search strategy resulted in 739 titles of which 34 articles met our criteria for full text inclusion for review (see Fig. 1). The PubMed (373) and Scopus (366) database provided 34 of these articles. In addition, three more articles were found by checking the reference lists of the included full texts. The selected 37 eligible articles described 44 outbreaks of human psittacosis in twelve different countries over the period 1986 through 2014 (Table 1). Seven of the 16 larger outbreaks with ten or more cases, took place in poultry processing plants/ slaughterhouses and poultry farms [11-17]. Other larger outbreaks were related to a bird show or bird park [3, $18,19]$, at a veterinary teaching hospital [20], an aviary in an institution [21], a distribution of birds from the same breeder [22] and two were linked to wild birds in Australia [23, 24]. In one large outbreak transmission took place in hospital setting [25]. More than half of the articles $(21 / 37,57 \%)$ described one or more smaller outbreaks with two to nine people tested with laboratory methods. Eight [26-33] of these smaller outbreaks occurred at family homes and were linked to pet birds, six took place at poultry farms or poultry processing plants
[31, 34-38], three were linked to a (pet or other) shop [39-41], two described outbreaks at hospitals, with human psittacosis patients as source [42, 43], two concerned workers and students at a veterinary clinic or school [44, 45] and one was linked to a parrot relief and breeding center [46].

Psittacine birds were mentioned as possible sources in $43 \%(16 / 37)$ of the articles. Fifty-four percent (20/37) was linked to other birds of which $65 \%(13 / 20)$ to poultry. The articles of outbreaks at farms, breeders or processing plants all mentioned poultry, including chicken, ducks, geese, turkeys and peacocks, as possible source. In $16 \%(6 / 37)$ of the included articles direct or indirect contact with wild birds (for example: psittacines, pigeons, gulls, wild bird feathers or excrements), were considered possible sources [16, 23-25, 43, 44]. Exposure to an equine fetal membrane caused a small outbreak at a veterinary school and equine stud farm [45]. Some outbreaks occurred after hospitalization of a bird-infected index case, which spread the infection person-to-person amongst their contacts [25, 43].

\section{Laboratory tests used}

In the included psittacosis outbreaks, culture, serology and PCR were the types of laboratory procedures that were performed to diagnose psittacosis or to exclude pathogens other than C. psittaci (e.g. Legionella, Mycoplasma) or cross reactivity (e.g., C. pneumoniae, C. trachomatis) (Table 1). Most articles describe combinations of these tests but in seven articles, all published before 1998, only one test was used to diagnose C. psittaci infection.

\section{Serology}

In all of the included articles, at least one serological test was used. These were complement fixation tests (CFT), enzyme(-linked) immunosorbent assay tests (ELISA/EIA including recombinant ELISA), (micro-)immunofluorescence tests and whole cell immunofluorescence tests (IF/MIF/WHIF) and immuno-peroxidase tests (IPA). IF/ MIF (including IPA [15, 31, 32] and WHIF [34]) was used in the majority of the articles (27/37, 73\%), followed by CFT $(20 / 37,54 \%)$ and EIA/ELISA testing (5/37, 14\%). CFT and IF were used regularly in outbreak investigations from 1985 up to 2014 in contrast to ELISA/EIA. Only in the period 2003-2007 [16, 20, 36, 46] and thereafter in 2014 [45] ELISA/EIA testing was found in our review.

In many articles problems occurred with the (un-)availability of convalescent serum samples needed for confirmation of cases or the second sample did not show seroconversion, which makes interpretation and conclusions difficult. Clinical symptoms, in combination with suspected test results, made assumption of 


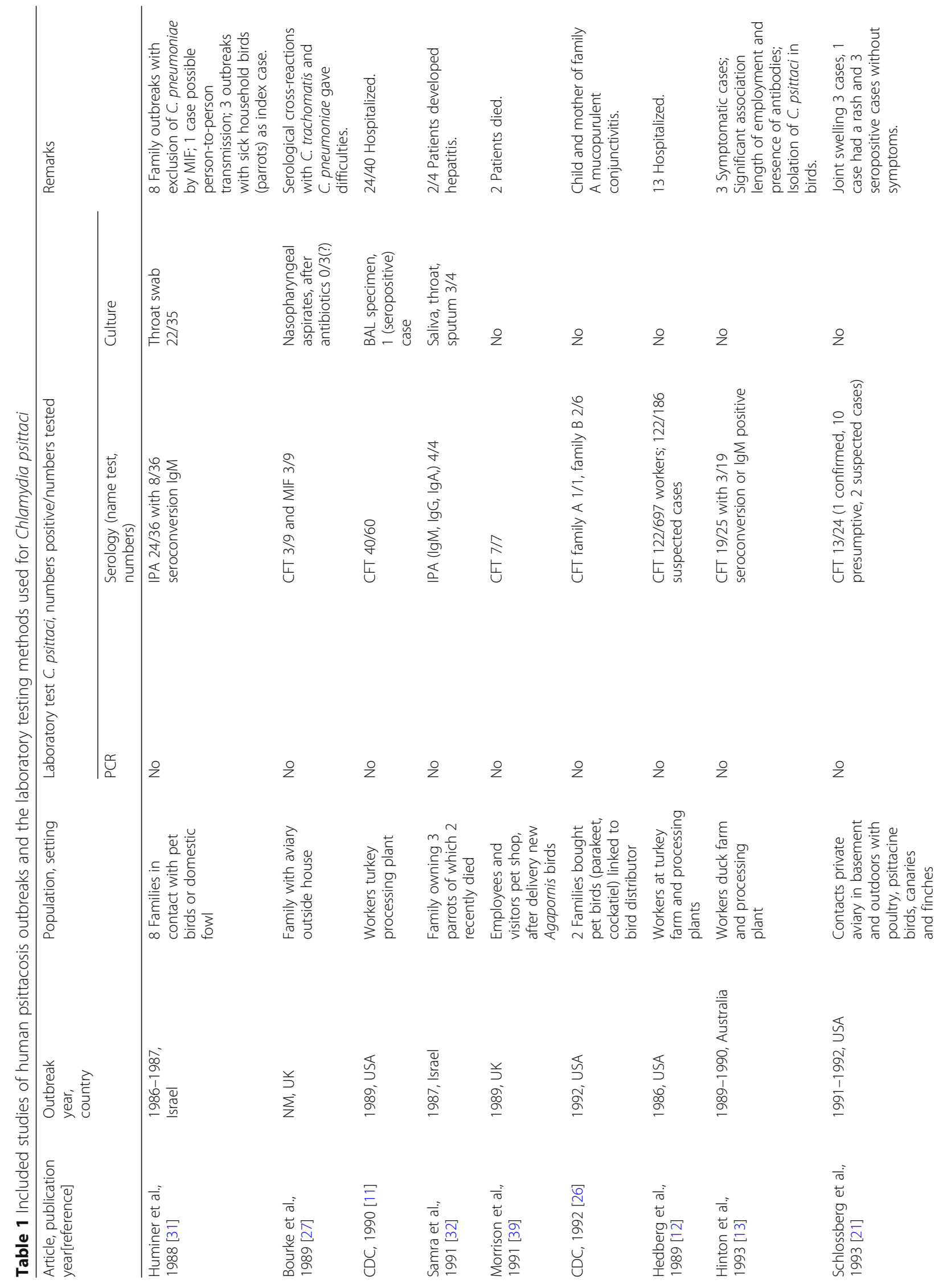




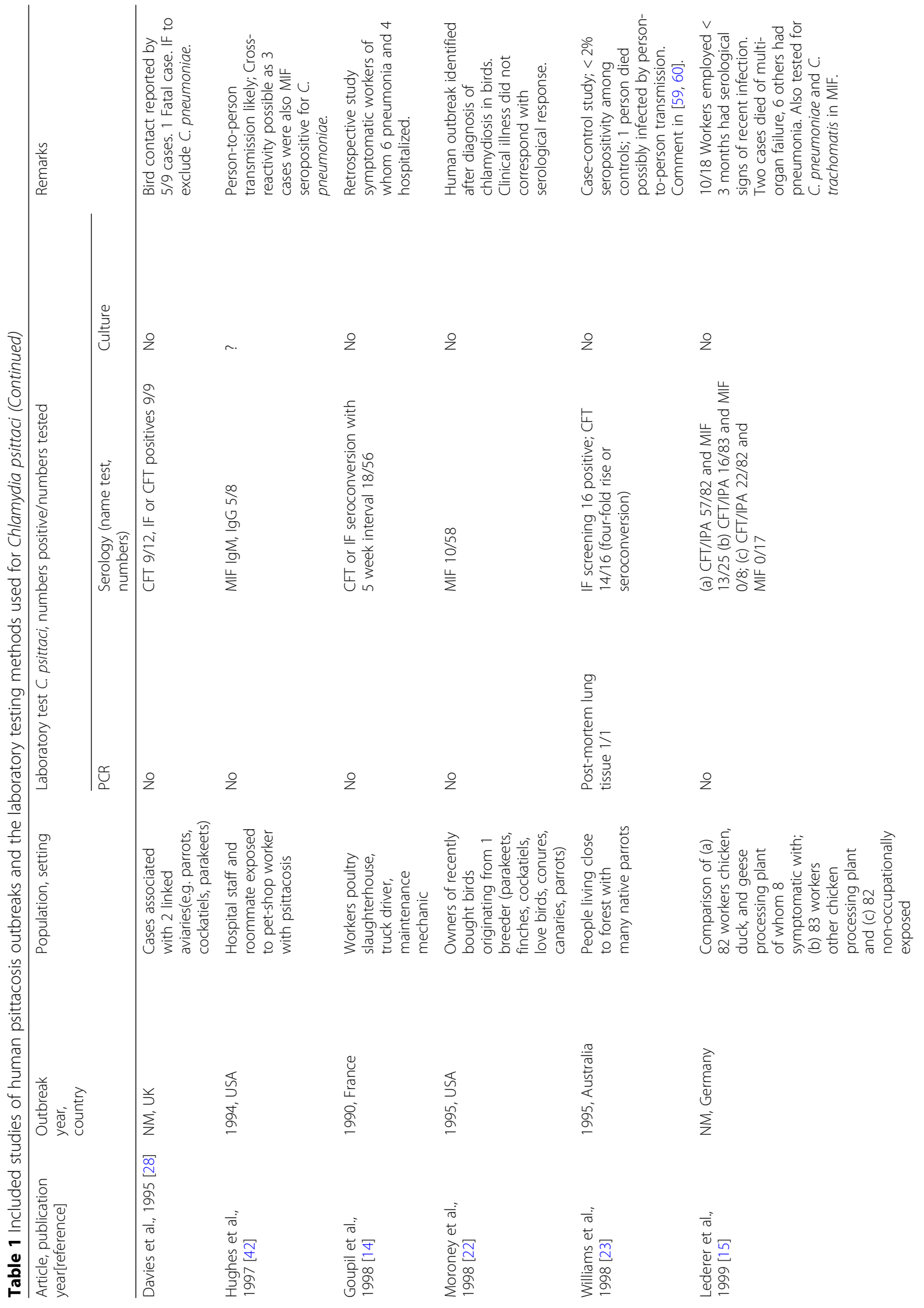




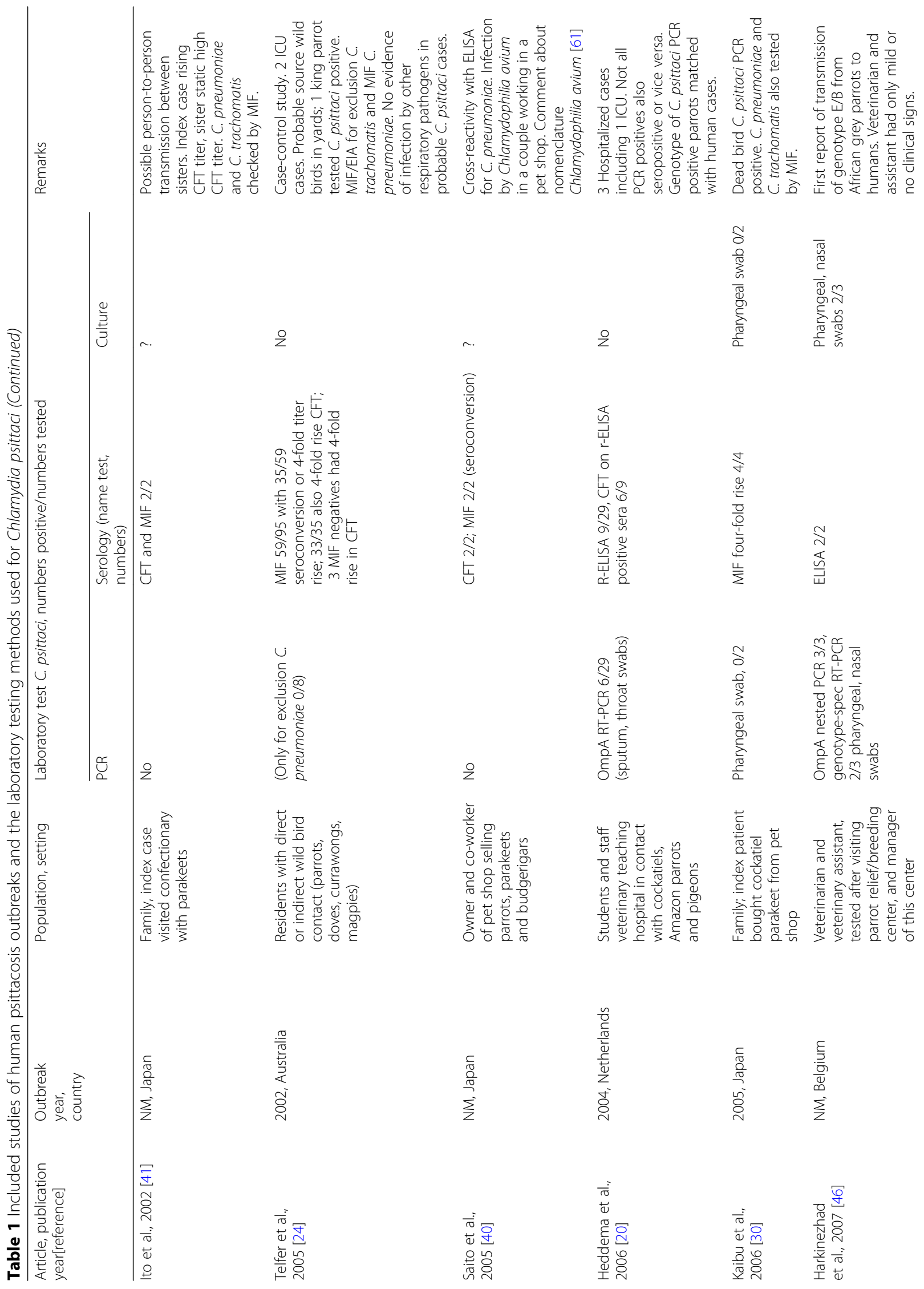




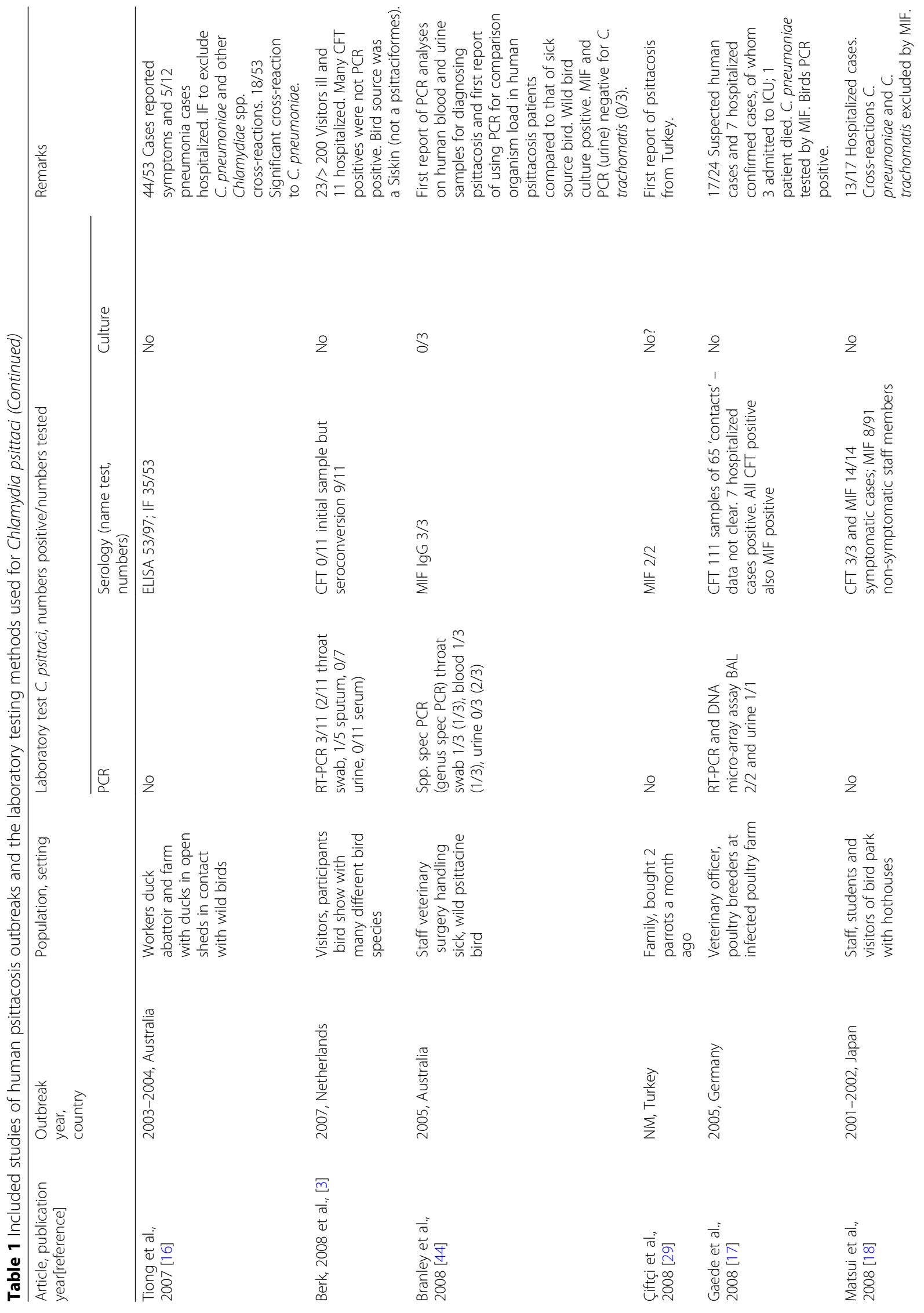




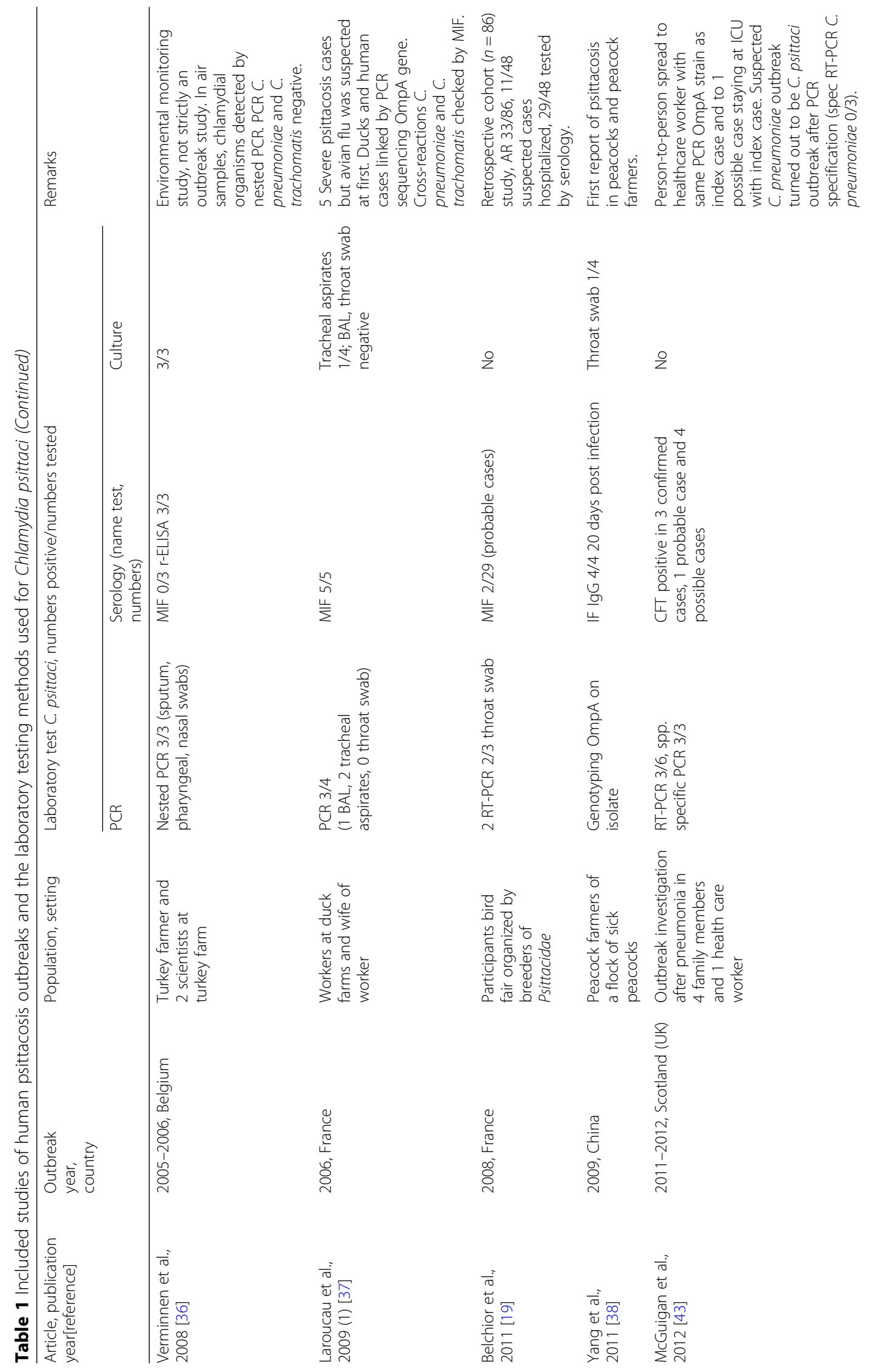




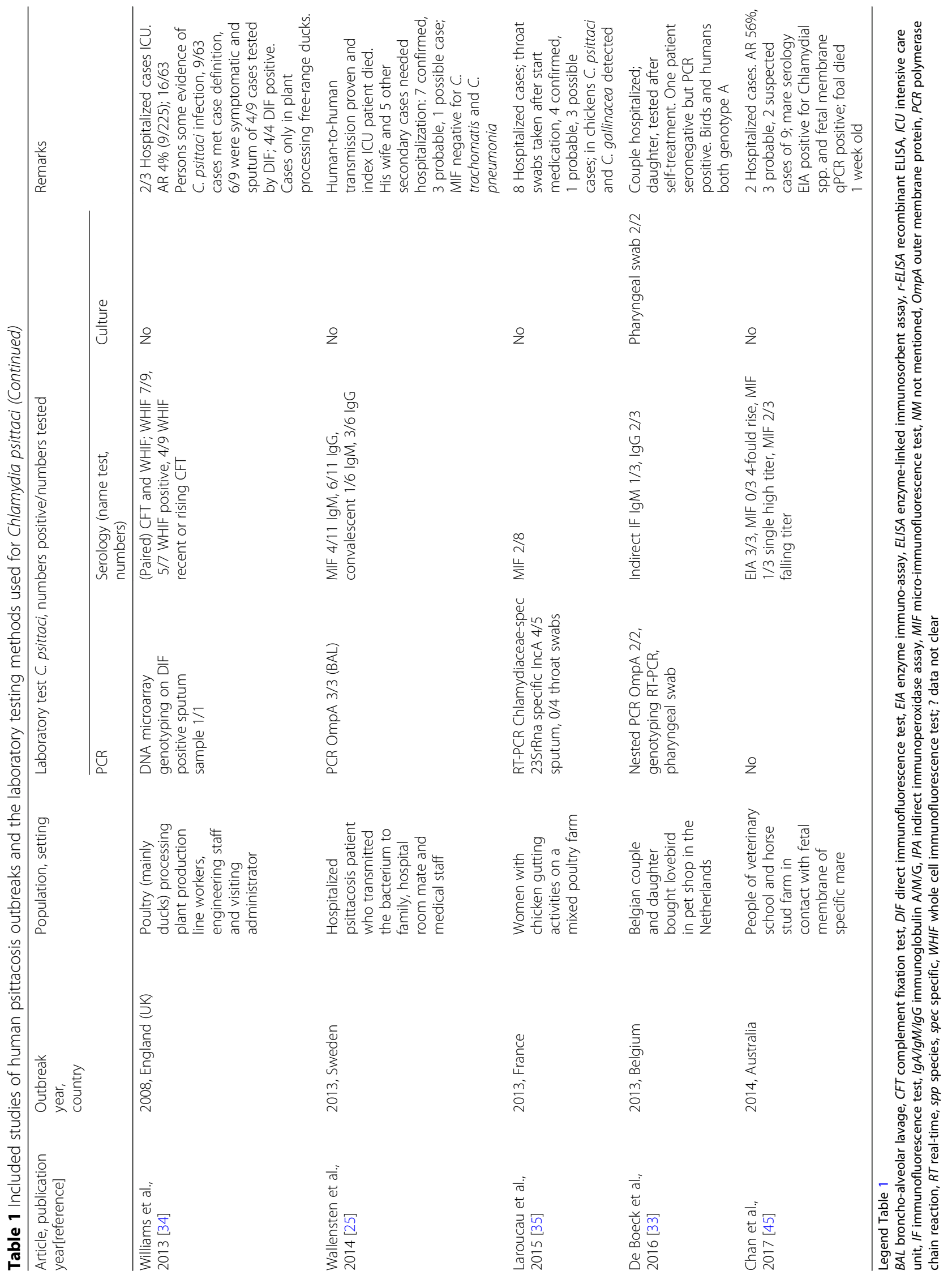


a positive psittacosis infection case more acceptable for positive interpretation.

\section{PCR}

PCR for laboratory diagnosis of C. psittaci was reported in 16 articles (16/37, 43\%). In 2006, Heddema et al. were the first to describe PCR to identify C. psittaci in humans in an outbreak situation in 2004, although Williams et al. (1998) performed PCR on human lung tissue postmortem of one single case in 1995 [20, 23]. Telfer et al. (2005) used a $C$. pneumoniae-specific PCR on hospitalized case-patients to exclude C. pneumoniae in an outbreak in Australia in 2002 [24]. From 2006, PCR techniques to identify C. psittaci in human patients were reported in 15 of 19 (79\%) of the included articles. PCR was used only in addition to a serologic testing method, while culture was used next to PCR in seven of the 15 PCR articles (47\%). PCR was mainly performed on hospitalized patient samples. Among the articles, the PCR testing methods described differed in DNA targets, in species and genus specificity, and in amplification and detection techniques. In addition, there was variation in the sampled clinical material used for PCR testing. We found BAL, sputum, throat swabs, nasal and pharyngeal swabs, blood and urine as test material taken for PCR. BAL and sputum are considered the best material for performing C. psittaci PCR, but this was often not available. Easier to collect are nasal, pharyngeal and throat swabs, blood and urine. Verminnen et al. (2008) reported pharyngeal and nasal swabs to be more suitable than sputum but this could be due to problems to produce sputum in many patients [36]. Only in two studies more than 10 people were tested with PCR. Fifty percent $(4 / 8)$ of the sputum samples and $14 \%(5 / 37)$ of the throat swabs tested PCR positive in these larger studies [3,20]. For the other outbreaks, the numbers of cases tested with PCR were small. Throat swabs scored less frequently positive (17\%, 8 / 48) compared to nasal and pharyngeal swabs, BAL and sputum. Nasal swabs scored best of the swabs $(100 \%, n=5)$ comparable with BAL $(100 \%, n=6)$ followed by sputum $(71 \%, 12 / 17)$ and pharyngeal swabs $(70 \%, 7 / 10)$. Urine was used for PCR in three outbreaks [3, 17, 44]. Gaede et al. (2008) reported C. psittaci genotype A detection in urine of a BAL positive patient [17]. Williams et al. (2013) used direct immunofluorescence test (DIF) on sputum samples and performed DNA micro-array based genotyping on one DIF positive sample [34].

Figure 2 shows an overview of serology tests and PCR used in the psittacosis outbreaks of selected outbreak articles over time.

\section{Culture}

Culture for C. psittaci was described in 30\% (11/37) of all the articles, always in addition to other tests. Culturing C. psittaci was used mostly to confirm the outcome of the serological test(s) and/or PCR in one or a few index cases. Culturing other agents was done to be able to exclude these as causative pathogens. Culture was still used several times after PCR testing became available $(58 \%, 7 / 12)$ (Table 1) although biosafety level three is needed and C. psittaci culture is not routinely performed in most diagnostic laboratories. BAL or sputum, pharyngeal aspirates or swabs are considered the best materials for culturing C. psittaci, and comparable to best material for PCR tests taken in the acute phase of infection.

In some articles included in the review that mentioned culture, it was not clear whether this was specifically for C. psittaci, or referred to routine (blood, sputum, urine) culture for other possible pathogens of respiratory infections. None of the blood cultures identified C. psittaci. This might indicate blood culture was performed mainly for other agents. Culturing of sputum (or other respiratory material) was more likely to include C. psittaci and more often reported positive results compared to blood cultures.

\section{Best practice}

We did not find a standard algorithm or uniformity in testing methods. Wide varieties of testing methods and various sorts of combinations of these have been used. Each of these testing strategies was intended to deal with the low specificity and/or sensitivity of some of the individual tests and the availability of test material at the right moment during an infection period. A general tactic described in the articles in this review, both for PCR and for serology, is the use of a genus specific test as a first step, followed by a more specific (i.e. species-specific) test to exclude other chlamydial species, especially C. pneumoniae and C. trachomatis. Besides testing strategies to diagnose C. psittaci, many articles describe additional diagnostic tests to exclude other pathogens that may cause comparable clinical syndromes, especially influenza like illnesses and community acquired pneumonia (CAP). These tests may act as a first step in multi-stage testing. Testing for $C$. psittaci will be considered only after exclusion of those other pathogens, or when e.g. history of bird contact or other circumstances are suggestive for psittacosis. These first stage tests to exclude other pathogens are beyond the scope of this review.

Comprehensive testing strategies for outbreak situations were found in the articles of Heddema et al. (2006) [20] and of Belchior et al. (2011) [19]. In an outbreak at a veterinary teaching hospital, Heddema et al. (2006) used PCR [47] in as many subjects as possible in combination with serology (CFT and ELISA on paired samples) for human case finding. In addition, they performed PCR among potential bird sources for veterinary case finding and culture to exclude other human respiratory pathogens. In an outbreak study related to a bird show, Belchior et al. 


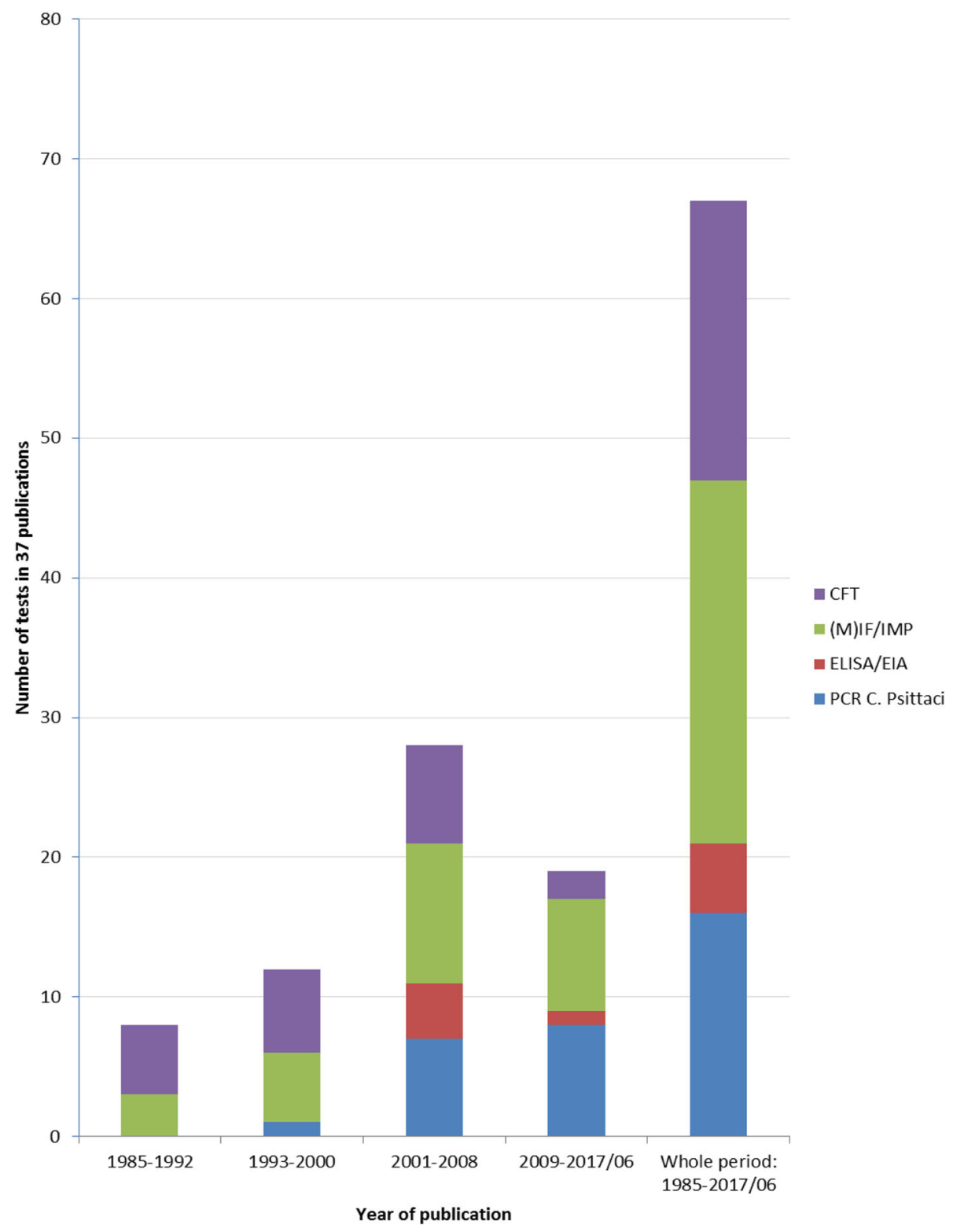

Fig. 2 History of serology and PCR testing in psittacosis outbreaks 1985-2014. ${ }^{* 1993-2000 ~ P C R ~ o n l y ~ o n ~ p o s t-m o r t e m ~ m a t e r i a l ~[34] ~}$

(2011) used serology (MIF) in combination with two different PCR tests (one targeting a C. psittaci-specific incA gene [48], and one targeting a Chlamydiaceae-specific 23S rRNA gene [49]) for human case finding. The latter PCR test was also used for veterinary source finding and genotypical matching but matching failed because genotyping of PCR positive human samples was impossible due to lack of sufficient DNA.

Both Heddema et al. (2006) and Belchior et al. (2011) were able to confirm C. psittaci as causative agent of the outbreak and exclude other chlamydial species. However, in both studies, only a few of the tested human cases could be confirmed despite early recognition of the outbreak. Most of the tested cases remained classified as 'possible C. psittaci'. Nevertheless, with the testing strategy of Heddema et al. (2006), the investigators were able to identify the (possible) source of the outbreak by a genotypic match between a bird source and human cases.

\section{Discussion}

In recent outbreaks in the Netherlands, serological laboratory test results to identify acute and non-acute human C. psittaci infections turned out to be non-specific, thereby precluding the monitoring of the number of confirmed cases, detection of possible sources, and identification of risk factors. The difficulties with laboratory 
testing strategies in outbreak settings prompted us to do a systematic review of the international literature of laboratory methods used in psittacosis outbreaks.

However, the main findings of the review are that a wide variety of (combinations of) testing methods are being used and that no (gold) standard or uniformity in testing strategies exists. For outbreak investigation, each single test method has drawbacks, ranging from low sensitivity or cross-reactivity with related species, to issues relating to the unfeasibility to collect the optimal clinical material at the optimal time intervals for the respective tests. It is clear that in a considerable number of cases (or tested individuals in an exposed cohort) in most psittacosis outbreaks, C. psittaci infection cannot be confirmed, nor can $C$. psittaci be excluded as causative pathogen. Although studies were found in which the investigators made considerable efforts to deal with known limitations of the single test methods, by collecting various sorts of clinical materials and using a broad combination of tests, none of these testing strategies seemed to be suitable for (nearly) full case finding.

\section{Evaluation of testing strategies}

The current existing test methods for C. psittaci can be divided into culture, PCR and various serological methods, namely CFT, ELISA/EIA, IF and IPA tests. In all outbreaks, serologic methods were used. However, because of cross reactivity with other Chlamydial species, serological testing of a serum sample taken at one single moment will not be sufficient for confirmation [50]. Therefore, PCR testing or culture, which have a higher specificity, can be performed in addition. For these test methods, clinical material from the lower respiratory tract is preferred, i.e. sputum or BAL [51]. However, these materials are frequently not available, especially not in outpatients, and considered as rather invasive to obtain. PCR is also being performed on other clinical material, like throat swabs, but then sensitivity is assumed to be considerably lower although few comparative studies have been performed [36, 51, 52]. Furthermore, PCR is only of use early in the infection and is therefore of limited value for retrospective case finding or investigating asymptomatic exposure.

To overcome the problems with the low specificity of single point serology, serological testing on convalescent sera can be performed, taken with an interval of several weeks but we found no standard for the optimal time interval. This approach has two disadvantages. First, sera from the acute phase of the illness are necessary, which is only possible if all cases or cohort members are sampled early in the outbreak. Second, samples from a few weeks later are necessary. This requires a sampling procedure that might be difficult to implement in practice. Taking convalescent sera is time consuming, expensive and is unlikely to be relevant for clinical management of individual patients, whose symptoms might have already subsided after presumptive antibiotic therapy. At present time, ELISA techniques lack specificity and IF techniques are more reliable when they are performed in 3-spot IF, including C. trachomatis, C. pneumoniae and C. psittaci. Finding a high IgM titer, in combination with clinical symptoms and/or history of a patient, can provide an early probable case diagnosis before waiting for the second serum sample for confirmation.

In outbreaks of psittacosis, there is often a considerable time delay between onset of symptoms in patients and laboratory diagnostic testing. History of bird contact may be absent. When history is not taken carefully and bird contact unknown, standard diagnostics in patients with pneumonia usually do not include tests for C. psittaci infection [53]. Therefore, many psittacosis index patients are discovered late and in hospital situations. Or, they might not be recognised due to lack of sensitivity of PCR because test material is taken long after start of infection and/or first serum samples do not show high antibody titres. Diagnosis confirmation by serology takes at least two weeks after taking the first sample, and is therefore always retrospective. Culturing C. psittaci also takes more time than PCR for specific diagnosis, is not easy and has the disadvantage that it has to be performed under biosafety level three laboratory conditions. PCR is on the other hand, a specific and fast method when performed on suitable acute phase respiratory material. If the possibility exists to use a $C$. psittaci specific PCR (and not a genus specific PCR), this is the most specific and fastest method to confirm an individual suspected psittacosis patient. Nevertheless, the delays as mentioned above hamper rapid specific diagnosis of psittacosis especially by PCR when bird contact is not obvious. Of course, the chosen testing strategy will depend also on the availability of tests, test material and their sensitivity and specificity in combination with the likelihood of a psittacosis case or possible outbreak in mind.

\section{Implications for epidemiological investigation}

In any psittacosis outbreak, confirmation of human cases will take some time, because of the incubation time of the disease, patient delay in seeking medical care, diagnostic delay (i.e. the time from first medical examination to a possible or confirmed diagnosis), and delay in recognition that there is a possible outbreak situation, after the first human and/or veterinary cases have occurred. In practice, this period might last several weeks. Therefore, delays in sampling of symptomatic cases and asymptomatic exposed people cannot be prevented. This means that full case finding with the current available laboratory methods for the diagnosis of C. psittaci, is 
impossible. Rather than trying to test all possible cases, it seems more efficient to focus on early confirmation of an outbreak based on PCR testing of only a few cases, i.e. confirm C. psittaci with laboratory methods in some epidemiological linked individuals. Genotyping of PCR-positive samples will facilitate source tracing. In addition, further risk factor analysis can then be based on a clinical case definition. However, with many probable and possible cases, based on such a clinical case definition, it will be difficult to obtain reliable estimates of disease burden.

\section{Limitations of the study}

Our review is based on three decades of international literature on laboratory-testing strategies used for the diagnosis of C. psittaci in human psittacosis outbreaks. Unfortunately, we had to exclude 18 potential relevant articles because of the language or because we were not able to retrieve the full text. However, the English abstracts of these excluded articles, when available, did not describe deviating methods, settings or populations from the included literature.

Another difficulty in the selection process of articles was when more than one case was described and we had to consider if the setting was an outbreak or not. Some interesting articles had unusual situation. Vorimore et al. (2015) described several psittacosis cases but we considered these more likely to be separate cases gathered over time than to be part of an outbreak. These cases worked on different duck farms with laying flocks but had duck insemination with semen from a single male flock, diagnosed as heavy shedders, in common [54]. Branley et al. (2014) described an endemic situation in Australia of community-acquired psittacosis in the period 20032009 but not an outbreak. Sixty percent of the cases did not have history of direct bird contact but indirect contact was universal. Moreover, only a low prevalence of $C$. pneumoniae was present [55]. The systematic review is complicated by the changes in nomenclature over the years, from Chlamydia to Chlamydophila psittaci and back, and the discovery of new Chlamydia subtypes. We excluded newly described non-avian strains, such as $C$. abortus, C. caviae, C. felis and C. pecorum, by restricting our search to $C$. psittaci outbreaks with a link to birds only and not to other animals. Outbreaks of human psittacosis without bird contact, i.e. caused by non-avian strains, have not been reported, although case reports have been published [56]. Recently, two more Chlamydiae species were described to infect birds i.e. $C$. avium and C. gallinacea. The zoonotic potential of these new species is not established well yet, but infection may not be detected by the currently available PCR tests for C. psittaci [57, 58]. Laroucau et al. (2015) describe human psittacosis cases in contact with C. gallinacea and $C$. psittaci co-infected poultry but C. gallinacea could not be identified in the human cases [35].

Another challenge for the present review was that laboratory methods and case definitions in the included articles often were described poorly and differed between outbreaks. Therefore, it was difficult to categorize the reported laboratory methods and to assess the number of cases tested positive.

\section{Conclusion}

PCR enables rapid identification of acute symptomatic and asymptomatic human psittacosis patients and helps source finding by genotyping in outbreaks. However, sensitivity of PCR declines rapidly in the time period between onset of illness and seeking medical care and performing laboratory testing. Moreover, suitable material to use for PCR testing is not easily available. We conclude that there is a need for new serologic testing methods next to PCR, with good specificity and sensitivity, preferably in a single sample, for confirmation of psittacosis cases in outbreaks.

\section{Additional file}

Additional file 1: Search Strategies. (DOCX $14 \mathrm{~kb}$ )

\section{Abbreviations}

AR: Attack Rate; BAL: Broncho-alveolar lavage; C. abortus: Chlamydia abortus; C. avium: Chlamydia avium; C. caviae: Chlamydia caviae; C. felis: Chlamydia felis; C. gallinacea: Chlamydia gallinacea; C. pecorum: Chlamydia pecorum; C. pneumoniae: Chlamydia pneumoniae; C. psittaci: Chlamydia psittaci; C. trachomatis: Chlamydia trachomatis; CFT: Complement fixation test; DIF: Direct immunofluorescence test; DNA: Deoxyribonucleic acid; EIA: Enzyme immuno-assay; ELISA: Enzyme-linked immunosorbent assay; ICU: Intensive care unit; IF: Immunofluorescence test; IgA/lgM/ IgG: Immunoglobulin A/M/G; IPA: Indirect immunoperoxidase assay; MESH: Medical Subject Headings; MIF: Micro-immunofluorescence test; NM: Not mentioned; OmpA: Outer membrane protein; PCR: Polymerase chain reaction; PRISMA: Preferred Reporting Items for Systematic Reviews and Meta-Analysis; r-ELISA: Recombinant ELISA; RT: Real-time; spec: Specific; spp.: Species; TWAR: Taiwan acute respiratory agent; WHIF: Whole cell immunofluorescence test

\section{Acknowledgements}

We would like to thank Wim ten Have, information specialist at RIVM for his assistance with the literature search strategies as well as Barbara Schimmer and Nancy Reedijk for their contribution to the background section.

\section{Funding}

This study was funded from the regular budget of the Centre for Infectious Disease Control (project number V/150207) and from the Plat4m-2Bt-psittacosis project, granted by ZonMw, the Netherlands Organisation for Health Research and Development (project number 522001002).

The funders had no role in study design, data collection and analysis, decision to publish, or preparation of the manuscript.

\section{Availability of data and materials}

All data generated or analysed during this study are included in this published article and/or its supplementary information files. 


\section{Authors' contributions}

WvdH conceived the study. AN and FD designed search strategy. Study selection: AN, FD, WvdH. Initial draft and writing manuscript: AN; Data extraction and analysis for Table 1: AN, FD; DN gave feedback for Table 1 and reviewed manuscript. AN, FD, DN, WvdH were major contributors in writing the manuscript. Supervision: FD and WvdH. All authors reviewed and revised the manuscript. All authors read and approved the final manuscript.

\section{Ethics approval and consent to participate}

Not applicable.

\section{Consent for publication}

Not applicable.

\section{Competing interests}

The authors declare that they have no competing interests.

\section{Publisher's Note}

Springer Nature remains neutral with regard to jurisdictional claims in published maps and institutional affiliations.

\section{Author details \\ ${ }^{1}$ Centre for Infectious Diseases, Epidemiology and Surveillance, Centre for Infectious Disease Control, National Institute for Public Health and the Environment (RIVM), Bilthoven, The Netherlands. ${ }^{2}$ Centre for Infectious Diseases Research, Diagnostics and Laboratory Surveillance, Centre for Infectious Disease Control, National Institute for Public Health and the Environment (RIVM), Bilthoven, The Netherlands.}

\section{Received: 26 April 2018 Accepted: 7 August 2018}

\section{Published online: 30 August 2018}

\section{References}

1. Kaleta EF, Taday EM. Avian host range of Chlamydophila spp. based on isolation, antigen detection and serology. Avian Pathol. 2003;32(5): 435-61.

2. Koene R, Hautvast J, Zuchner L, Voorn P, Rooyackers-Lemmens E, Noel H, Swaan C. Local cluster of psittacosis after bird show in the Netherlands, November 2007. Euro Surveill. 2007;12(12):E071213.071211.

3. Berk Y, Klaassen CH, Mouton JW, Meis JF. An outbreak of psittacosis at a bird-fanciers fair in the Netherlands. Ned Tijdschr Geneeskd. 2008;152(34): 1889-92.

4. Van der Hoek W, van Gageldonk-Lafeber A, Heddema E, Notermans D, Den Boer J, Nieuwenhuizen A, Tjon-A-Tsien A, Dijkstra F, Meijer A. Omvang van het psittacose-probleem bij de mens: het belang van betrouwbare diagnostiek. Infectieziekten Bulletin. 2014;25(2):45-8.

5. Schimmer $B N H$, Koene $R$, van de Velden $K J$, Züchner $L$, van der Lubben $\mathrm{M}$ et al.: An outbreak of psittacosis after a bird show, the Netherlands 2007. 4th Med-Vet-Net Annual Scientific Conference 2008 (poster) 2008

6. Graveland H, Roest $H$, Stenvers $\mathrm{O}$, Valkenburgh S, Friesema I, Van der Giessen J. Staat van zoönosen 2012 [State of zoonoses]. Bilthoven: National Institute for Public Health and the Environment (RIVM); 2013.

7. Grayston JT, Kuo CC, Wang SP, Altman J. A new chlamydia psittaci strain, TWAR, isolated in acute respiratory tract infections. N Engl J Med. 1986; 315(3):161-8.

8. Kuo CC, Chen HH, Wang SP, Grayston JT. Identification of a new group of chlamydia psittaci strains called TWAR. J Clin Microbiol. 1986;24(6): 1034-7.

9. Pether JV, Noah ND, Lau YK, Taylor JA, Bowie JC. An outbreak of psittacosis in a boys' boarding school. J Hyg (Lond). 1984;92(3):337-43.

10. Pether JV, Wang SP, Grayston JT. Chlamydia pneumoniae, strain TWAR, as the cause of an outbreak in a boys' school previously called psittacosis. Epidemiol Infect. 1989;103(2):395-400.

11. Psittacosis at a turkey processing plant--North Carolina, 1989. MMWR Morb Mortal Wkly Rep. 1990;39(27):460-1. 467-469

12. Hedberg K, White KE, Forfang JC, Korlath JA, Friendshuh KA, Hedberg CW, MacDonald KL, Osterholm MT. An outbreak of psittacosis in Minnesota Turkey industry workers: implications for modes of transmission and control. Am J Epidemiol. 1989;130(3):569-77.
13. Hinton DG, Shipley A, Galvin JW, Harkin JT, Brunton RA. Chlamydiosis in workers at a duck farm and processing plant. Aust Vet J. 1993:70(5):174-6.

14. Goupil F, Pelle-Duporte D, Kouyoumdjian S, Carbonnelle B, Tuchais E. Severe pneumonia with a pneumococcal aspect during an ornithosis outbreak. Presse Med. 1998;27(22):1084-8.

15. Lederer $P$, Muller R. Ornithosis--studies in correlation with an outbreak. Gesundheitswesen. 1999;61(12):614-9.

16. Tiong A, Vu T, Counahan M, Leydon J, Tallis G, Lambert S. Multiple sites of exposure in an outbreak of ornithosis in workers at a poultry abattoir and farm. Epidemiol Infect. 2007;135(7):1184-91.

17. Gaede W, Reckling KF, Dresenkamp B, Kenklies S, Schubert E, Noack U, Irmscher HM, Ludwig C, Hotzel H, Sachse K. Chlamydophila psittaci infections in humans during an outbreak of psittacosis from poultry in Germany. Zoonoses Public Health. 2008;55(4):184-8.

18. Matsui T, Nakashima K, Ohyama T, Kobayashi J, Arima Y, Kishimoto T, Ogawa M, Cai $Y$, Shiga $S$, Ando S, et al. An outbreak of psittacosis in a bird park in Japan. Epidemiol Infect. 2008;136(4):492-5.

19. Belchior E, Barataud D, Ollivier R, Capek I, Laroucau K, de Barbeyrac B, Hubert B. Psittacosis outbreak after participation in a bird fair, western France, December 2008. Epidemiol Infect. 2011;139(10):1637-41.

20. Heddema ER, van Hannen EJ, Duim B, de Jongh BM, Kaan JA, van Kessel R, Lumeij JT, Visser CE, Vandenbroucke-Grauls CM. An outbreak of psittacosis due to Chlamydophila psittaci genotype a in a veterinary teaching hospital. J Med Microbiol. 2006;55(11):1571-5.

21. Schlossberg D, Delgado J, Moore MM, Wishner A, Mohn J. An epidemic of avian and human psittacosis. Arch Intern Med. 1993;153(22):2594-6.

22. Moroney JF, Guevara R, Iverson C, Chen FM, Skelton SK, Messmer TO, Plikaytis B, Williams PO, Blake P, Butler JC. Detection of chlamydiosis in a shipment of pet birds, leading to recognition of an outbreak of clinically mild psittacosis in humans. Clin Infect Dis. 1998;26(6):1425-9.

23. Williams J, Tallis G, Dalton C, Ng S, Beaton S, Catton M, Elliott J, Carnie J. Community outbreak of psittacosis in a rural Australian town. Lancet. 1998; 351(9117):1697-9.

24. Telfer BL, Moberley SA, Hort KP, Branley JM, Dwyer DE, Muscatello DJ, Correll PK, England J, MCAnulty JM. Probable psittacosis outbreak linked to wild birds. Emerg Infect Dis. 2005:11(3):391-7.

25. Wallensten A, Fredlund $H$, Runehagen A. Multiple human-to-human transmission from a severe case of psittacosis, Sweden, January-February 2013. Euro Surveill. 2014;19(42):20937.

26. Human psittacosis linked to a bird distributor in Mississippi--Massachusetts and Tennessee, 1992. MMWR Morb Mortal Wkly Rep. 1992;41(42):794-7.

27. Bourke SJ, Carrington D, Frew CE, Stevenson RD, Banham SW. Serological cross-reactivity among chlamydial strains in a family outbreak of psittacosis. J Inf Secur. 1989:19(1):41-5.

28. Davies A, Collins T. Respiratory chlamydia: the management of an outbreak. Public Health. 1995;109(3):207-11.

29. Ciftci B, Guler ZM, Aydogdu M, Konur O, Erdogan Y. Familial outbreak of psittacosis as the first chlamydia psittaci infection reported from Turkey. Tuberk Toraks. 2008:56(2):215-20.

30. Kaibu H, lida K, Ueki S, Ehara H, Shimasaki Y, Watanabe S, Anzai H, Takebu W, Muta T, Kusaba T, et al. Psittacosis in all four members of a family in Nagasaki Japan. Jpn J Infect Dis. 2006;59(5):349-50.

31. Huminer D, Samra Z, Weisman Y, Pitlik S. Family outbreaks of psittacosis in Israel. Lancet. 1988;2(8611):615-8.

32. Samra Z, Pik A, Guidetti-Sharon A, Yona E, Weisman Y. Hepatitis in a family infected by chlamydia psittaci. J R Soc Med. 1991;84(6):347-8.

33. DeBoeck C, DeHollogne C, Dumont A, Spierenburg M, Heijne M, Gyssens I, VDH J, Vanrompay D. Managing a cluster outbreak of psittacosis in Belgium linked to a pet shop visit in the Netherlands. Epidemiol Infect. 2016;144(8): 1710-6.

34. Williams CJ, Sillis M, Fearne V, Pezzoli L, Beasley G, Bracebridge S, Reacher M, Nair P. Risk exposures for human ornithosis in a poultry processing plant modified by use of personal protective equipment: an analytical outbreak study. Epidemiol Infect. 2013;141(9):1965-74

35. Laroucau K, Aaziz R, Meurice L, Servas V, Chossat I, Royer H, de Barbeyrac B, Vaillant $\mathrm{V}$, Moyen $\mathrm{J}$, Meziani $\mathrm{F}$, et al. Outbreak of psittacosis in a group of women exposed to Chlamydia psittaci-infected chickens. Euro Surveill. 2015;20(24):21155.

36. Verminnen K, Duquenne B, De Keukeleire D, Duim B, Pannekoek Y Braeckman L, Vanrompay D. Evaluation of a Chlamydophila psittaci infection diagnostic platform for zoonotic risk assessment. J Clin Microbiol. 2008;46(1):281-5. 
37. Laroucau K, de Barbeyrac B, Vorimore F, Clerc M, Bertin C, Harkinezhad T, Verminnen K, Obeniche F, Capek I, Bebear C, et al. Chlamydial infections in duck farms associated with human cases of psittacosis in France. Vet Microbiol. 2009;135(1-2):82-9.

38. Yang J, Ling Y, Yuan J, Pang W, He C. Isolation and characterization of peacock Chlamydophila psittaci infection in China. Avian Dis. 2011;55(1):76-81.

39. Morrison WM, Hutchison RB, Thomason J, Harrington JH, Herd GW. An outbreak of psittacosis. J Inf Secur. 1991;22(1):71-5.

40. Saito T, Ohnishi J, Mori Y, linuma Y, Ichiyama S, Kohi F. Infection by Chlamydophilia avium in an elderly couple working in a pet shop. J Clin Microbiol. 2005;43(6):3011-3.

41. Ito I, Ishida T, Mishima M, Osawa M, Arita M, Hashimoto T, Kishimoto T. Familial cases of psittacosis: possible person-to-person transmission. Intern Med. 2002;41(N7):580-3.

42. Hughes C, Maharg P, Rosario P, Herrell M, Bratt D, Salgado J, Howard D. Possible nosocomial transmission of psittacosis. Infect Control Hosp Epidemiol. 1997;18(3):165-8.

43. CC MG, PG MI, Templeton K. Psittacosis outbreak in Tayside, Scotland, December 2011 to February 2012. Euro Surveill. 2012;17(22):20186.

44. Branley JM, Roy B, Dwyer DE, Sorrell TC. Real-time PCR detection and quantitation of Chlamydophila psittaci in human and avian specimens from a veterinary clinic cluster. Eur J Clin Microbiol Infect Dis. 2008;27(4):269-73.

45. Chan J, Doyle B, Branley J, Sheppeard V, Gabor M, Viney K, Quinn H, Janover $\mathrm{O}, \mathrm{McCready} \mathrm{M}$, Heller J. An outbreak of psittacosis at a veterinary school demonstrating a novel source of infection. One Health. 2017:3:29-33.

46. Harkinezhad T, Verminnen K, Van Droogenbroeck C, Vanrompay D. Chlamydophila psittaci genotype E/B transmission from African grey parrots to humans. J Med Microbiol. 2007;56(8):1097-100.

47. Heddema ER, Beld M, de Wever B, Langerak AAJ, Pannekoek Y, Duim B. Development of an internally controlled real-time PCR assay for detection of Chlamydophila psittaci in the LightCycler 2.0 system. Clin Microbiol Infect. 2006:12(6):571-5.

48. Menard A, Clerc M, Subtil A, Mégraud F, Bébéar C, de Barbeyrac B. Development of a real-time PCR for the detection of chlamydia psittaci. J Med Microbiol. 2006;55(4):471-3.

49. Ehricht R, Slickers P, Goellner S, Hotzel H, Sachse K. Optimized DNA microarray assay allows detection and genotyping of single PCR-amplifiable target copies. Mol Cell Probes. 2006;20(1):60-3.

50. Tuuminen T, Palomaki P, Paavonen J. The use of serologic tests for the diagnosis of chlamydial infections. J Microbiol Methods. 2000;42(3): 265-79.

51. Huijskens EG, Rossen JW, Kluytmans JA, van der Zanden AG, Koopmans M. Evaluation of yield of currently available diagnostics by sample type to optimize detection of respiratory pathogens in patients with a communityacquired pneumonia. Influenza Other Respir Viruses. 2014;8(2):243-9.

52. Cho MC, Kim H, An D, Lee M, Noh SA, Kim MN, Chong YP, Woo JH. Comparison of sputum and nasopharyngeal swab specimens for molecular diagnosis of mycoplasma pneumoniae, Chlamydophila pneumoniae, and legionella pneumophila. Ann Lab Med. 2012;32(2):133-8.

53. Spoorenberg SM, Bos WJ, van Hannen EJ, Dijkstra F, Heddema ER, van Velzen-Blad H, Heijligenberg R, Grutters JC, de Jongh BM. Chlamydia psittaci: a relevant cause of community-acquired pneumonia in two Dutch hospitals. Neth J Med. 2016;74(2):75-81.

54. Vorimore F, Thebault A, Poisson S, Cleva D, Robineau J, de Barbeyrac B, Durand B, Laroucau K. Chlamydia psittaci in ducks: a hidden health risk for poultry workers. Pathog Dis. 2015;73(1):1-9.

55. Branley JM, Weston KM, England J, Dwyer DE, Sorrell TC. Clinical features of endemic community-acquired psittacosis. New Microbes New Infect. 2014; 2(1):7-12.

56. Knittler MR, Sachse K. Chlamydia psittaci: update on an underestimated zoonotic agent. Pathog Dis. 2015;73(1):1-15.

57. Sachse K, Laroucau K. Two more species of chlamydia-does it make a difference? Pathog Dis. 2015;73(1):1-3.

58. Sachse K, Laroucau K, Riege K, Wehner S, Dilcher M, Creasy HH, Weidmann M, Myers G, Vorimore F, Vicari N, et al. Evidence for the existence of two new members of the family Chlamydiaceae and proposal of chlamydia avium sp. nov. and chlamydia gallinacea sp. nov. Syst Appl Microbiol. 2014; 37(2):79-88
59. Peeling R, Mabey D. Outbreak of chlamydia infection in rural Australian town. Lancet. 1998:352(9139):1551.

60. Catton M, Williams J. Psittacosis in a rural Australian town. Lancet. 1998; 352(9143):1861.

61. Greco G, Corrente M, Martella V. Detection of Chlamydophila psittaci in asymptomatic animals. J Clin Microbiol. 2005;43(10):5410-1. author reply 5410-5411

\section{Ready to submit your research? Choose BMC and benefit from:}

- fast, convenient online submission

- thorough peer review by experienced researchers in your field

- rapid publication on acceptance

- support for research data, including large and complex data types

- gold Open Access which fosters wider collaboration and increased citations

- maximum visibility for your research: over $100 \mathrm{M}$ website views per year

At BMC, research is always in progress.

Learn more biomedcentral.com/submissions 